\title{
Impact of Radio-frequency Atmospheric-pressure Plasma on Water Contact Angles of High-impact Polystyrene
}

\author{
Piotr Terebun, ${ }^{*}$ Michał Kwiatkowski, Paweł Mazurek, and Joanna Pawłat \\ Institute of Electrical Engineering and Electrotechnologies, Lublin University of Technology, \\ Nadbystrzycka 38A, 20-618 Lublin, Poland
}

(Received January 1, 2018; accepted April 23, 2018)

Keywords: atmospheric pressure plasmas, high-impact polystyrene, contact angles

For some applications of plastic materials, such as polystyrene, an important role is played by the wettability of the material. One of the methods of modifying material properties such as water contact angle is using nonthermal plasma. In this study, a radio-frequency atmospheric -pressure plasma jet source has been applied to the surface modification of a high-impact polystyrene film. The measurements show a dependence between the change in the water contact angle and the operating parameters of a nonequilibrium plasma treatment, such as the composition of the working gas, the flow rate, the distance from the plasma zone, and the discharge power.

\section{Introduction}

High-impact polystyrene (HIPS), owing to its satisfactory physical and mechanical properties, is one of the most common plastics. ${ }^{(1)}$ For some applications, an important role is played by the contact angle, which determines the hydrophobicity or hydrophilicity of the material. One of the methods of modifying material properties such as contact angle is using nonthermal plasma. ${ }^{(2-10)}$ The use of plasma may allow not only cost reduction but may also be more environmentally friendly. ${ }^{(10)}$ Additional reductions in manufacturing costs can be achieved by the use of plasma reactors, such as an atmospheric pressure plasma jet (APPJ) that does not require the use of a vacuum. Owing to the selectivity of energy, nonequilibrium plasma jet reactors also allow efficient physicochemical reactions to be carried out at relatively low gas temperatures, which do not cause changes in the bulk material. ${ }^{(2-5,11-15)}$ In this article, we present the results of research on water contact angles on HIPS exposed to nonequilibrium APPJ operating at a radio frequency of $14.36 \mathrm{MHz}$. The presented novelty of this paper is the use of a dedicated RF device, which enables working at atmospheric pressure, at relatively low temperatures, efficiently rendering a larger area of complicated shapes at a larger distance. Moreover, it allows working with mixtures of low amounts of noble carrier gases (such as helium) with a high ratio of reactive gases such as oxygen and air. All the above features help reduce the material modification costs. The measurements were performed for the main factors

*Corresponding author: e-mail: piotr.terebun@gmail.com

http://dx.doi.org/10.18494/SAM.2018.1891 
that affect the amount of generated active particles that reach the surface of the sample, namely, composition of working gas, discharge power, flow rate, and distance from the end of discharge.

\subsection{Atmospheric-pressure plasma jet}

One of the most important areas of application of plasma technology is the use of nonequilibrium plasma in environmental engineering, the food industry, and medicine. ${ }^{(2-5,16)}$ A nonequilibrium plasma is a plasma in which the electron energies are much larger than the energy of the other particles (ions and neutral particles) and with which it is possible to carry out a biochemical and physical reaction at a relatively low temperature of the working gas. This is particularly important in applications where high temperatures may be undesirable because they can damage the plasma-treated materials. For such applications, in the design of plasma reactors, the aim is to maintain the chemical composition of the working gas, pressure, and geometry of the discharge, which would allow reactions initiated by high-energy electrons to be carried out in a low-temperature plasma. Frequently, nonthermal plasma is used in indirect systems, where the interaction with the treated object does not take place through direct contact with the plasma but through the active particles generated in the plasma and carried along with the gas flow (afterglow effect). In addition to the impact of active particles in interactions (such as reactive oxygen and nitrogen species), an important role is played by the electromagnetic field, UV radiation, and drainage induced by the gas flow. In surface processing, plasma is primarily used for surface cleaning, deposition, ablation or etching, surface activation, crosslinking, and the formation of new functional groups. ${ }^{(17,18)}$ An example of a plasma reactor for these applications is a nozzle-shaped plasma jet reactor, inside of which the plasma is generated. ${ }^{(2,4,5,16,19)}$ Under forced gas flow, the plasma is transported outside the nozzle. The various types of reactors differ primarily in the configuration of electrodes, the type of gas, and the frequency of the power supply, which is in the range of several $\mathrm{kHz}$ to $\mathrm{GHz}$.

In this study, measurements were performed using a radio-frequency plasma jet with a high voltage electrode inside the nozzle (Fig. 1). The reactor operates at atmospheric pressure, which facilitates the plasma treatment and allows for a significant reduction in the cost of the process in industrial applications. The power supply uses a resonant circuit that enables the adjustment of the discharge power up to $50 \mathrm{~W}$. The resonant frequency depends on many factors, such as external conditions, the composition and flow rate of gas, and the shape and composition of the internal electrode, and it is selected individually for each case. The reactor allows working with oxygen, air, helium, argon, and mixtures thereof.

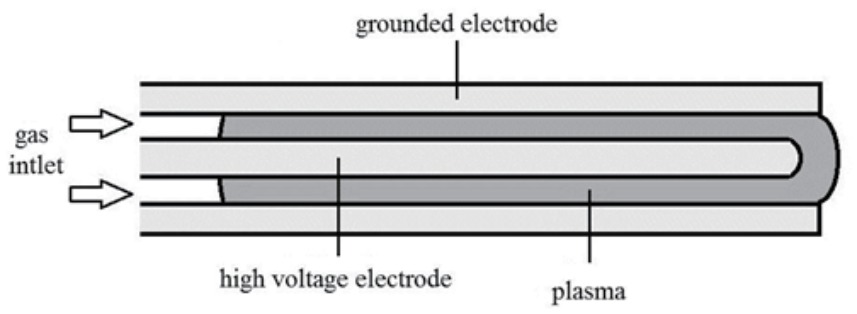

Fig. 1. Radio-frequency reactor. 


\subsection{Water contact angle}

For some polystyrene applications, an important role is played by the hydrophobicity or hydrophilicity of the material. Wettability is important, for example, in lithography, food packaging, self-cleaning, water repellency, inks and superhydrophobic coatings, disinfecting medical polymers, and particle attraction in DNA purification. ${ }^{(20-22)}$ One method of determining this parameter is to measure the contact angle. Contact angle is the angle formed by a solid flat surface and a tangential plane to the surface of a liquid. If the angle $\theta$ is higher than $90^{\circ}$, the material is hydrophobic; if it is lower, the material is hydrophilic [Fig. 2(a)].

One of the most common methods for measuring contact angle is the sessile drop method, which is based on the measurement of the angle formed by a droplet of liquid placed on a horizontal surface. ${ }^{(22,24)}$ The angle can be read, for example, using the half-angle technique, which consists of measuring the height and width of the drop [Fig. 2(b)] and calculating the angle using Eq. (1).

$$
\theta=2 \arctan \frac{h}{d}
$$

In measurements, deionized water, formamide, diiodomethane, or hexane are typically used as liquids. ${ }^{(24)}$

\section{Materials and Methods}

In this study, a commercially available high-impact polystyrene was used. Test samples were $30 \times 40 \mathrm{~mm}^{2}$ with a thickness of $2 \mathrm{~mm}$. The softening temperature of the material was $90{ }^{\circ} \mathrm{C} .{ }^{(25)}$ In the experiment, the operating voltage, frequency, and power of APPJ were $500 \mathrm{~V}$, 14.36 MHz, and 40-50 W, respectively. Measurements were made for three mixtures of gases: helium with oxygen, argon with oxygen, and helium with air. All measurements were made for gas temperatures below the softening temperatures of the material (Table 1).

By taking as reference the conditions for a mixture of helium and oxygen at a distance of $2 \mathrm{~cm}$, changes in the working gas composition caused temperature to increase by $12.7 \%$ for a mixture of helium and air and to decrease by $1.4 \%$ for argon and oxygen. Increasing the distance by $1 \mathrm{~cm}$ reduces temperature by $15.5 \%$ and increasing the flow rate by $50 \%$ reduces the temperature by about $25 \%$.

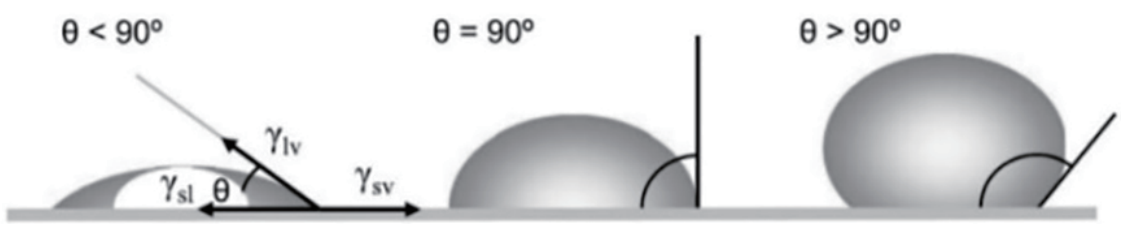

(a)

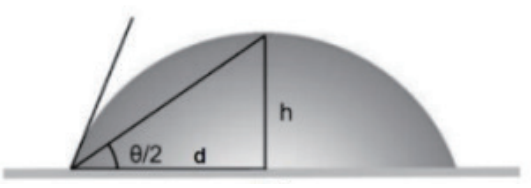

(b)

Fig. 2. Illustration of (a) contact angles formed by sessile liquid drops and (b) contact angle measurement. The terms $\gamma_{l v}, \gamma_{s v}$, and $\gamma_{s l}$ represent the liquid-vapor, solid-vapor, and solid-liquid interfacial tensions, respectively. ${ }^{(23)}$ 
Table 1

Gas temperature.

\begin{tabular}{lcccc}
\hline $\begin{array}{l}\text { Composition of gas } \\
\text { (proportions 3:2) }\end{array}$ & $\begin{array}{c}\text { Power } \\
(\mathrm{W})\end{array}$ & $\begin{array}{c}\text { Total flow rate } \\
\left(\mathrm{m}^{3} / \mathrm{h}\right)\end{array}$ & $\begin{array}{c}\text { Distance } \\
(\mathrm{cm})\end{array}$ & $\begin{array}{c}\text { Temperature } \\
\left({ }^{\circ} \mathrm{C}\right)\end{array}$ \\
\hline Helium + oxygen & 40 & 0.71 & 2 & 71 \\
Helium + oxygen & 40 & 0.71 & 2.5 & 62 \\
Helium + oxygen & 40 & 0.71 & 3 & 60 \\
Helium + oxygen & 50 & 0.71 & 3 & 61 \\
Helium + oxygen & 40 & 1.065 & 2 & 53 \\
Helium + air & 40 & 0.71 & 2 & 80 \\
Argon + oxygen & 40 & 0.71 & 2 & 70 \\
\hline
\end{tabular}

During the measurements, the reactor was directed perpendicularly to the surface of the sample (Fig. 3). Immediately after the plasma treatment, a $10 \mu 1$ drop of deionized water was injected onto the treated surface and pictures were taken with a CMOS camera. Calculations of average contact angle were performed using the half-angle method.

\section{Results and Discussion}

Examples of images obtained for a mixture of argon and oxygen are shown in Fig. 4. A significant change in the contact angle was visible after $5 \mathrm{~s}$ of plasma treatment. The results obtained for the different working gases are shown in Fig. 5. The smallest change was observed for a mixture of helium with air, but after 2 min of treatment, the angle decreased more than twofold compared with that of the control sample $\left(90^{\circ}\right)$. The better results obtained for mixtures containing oxygen can be explained by the presence of a larger number of oxygen active species (singlet oxygen, excited oxygen atom, and ozone), which can influence the behaviour of the sample surface. In these cases, $30 \mathrm{~s}$ of plasma treatment enabled the reduction in the contact angle of less than $23^{\circ}$.

Figure 6 shows the results for two flow rates of mixtures of helium and oxygen at the same proportion. Increasing the flow rate by $50 \%$ resulted in less impact on the contact angle, which may be explained by a higher flow gas spread over the surface of the sample and a lower concentration of active particles. The drying of the surface only by gas flow without plasma did not influence the surface properties.

The results obtained as a function of distance from the surface to the end of the reactor (Fig. 7) show the significant influence of distance when treatment times are less than $1 \mathrm{~min}$. For 2 min, the angle was similar for all distances, which may allow the objects with more complex surfaces to be treated more freely. Figure 8 shows the results for two power levels of discharge for mixtures of helium and oxygen at the same proportion. The increase in power from 40 to $50 \mathrm{~W}$ showed a slightly larger influence on the change in the contact angle for times less than 1 min; for longer times, the angle was almost the same. A higher power can be useful for shorter processing times from longer distances, because a decrease in distance at $50 \mathrm{~W}$ leads to an increase in temperature, which approaches the softening temperature of the material. 


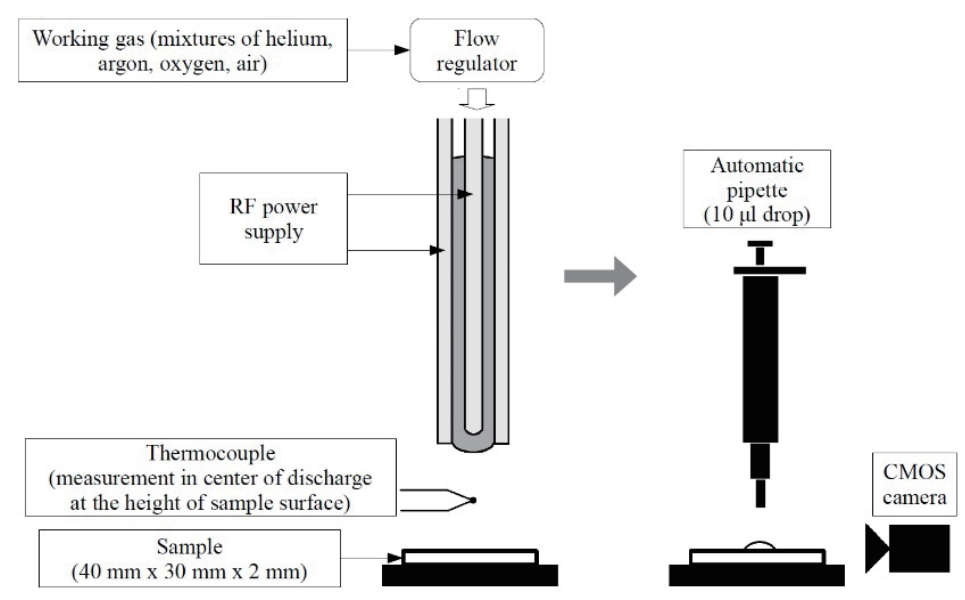

Fig. 3. Experimental setup.

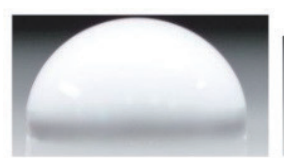

Control sample: $90^{\circ}$

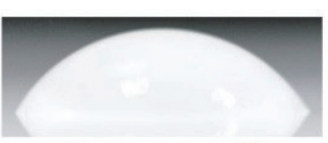

5 s treatment: $60^{\circ}$

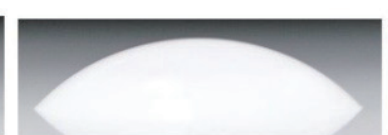

$10 \mathrm{~s}$ treatment: $46^{\circ}$

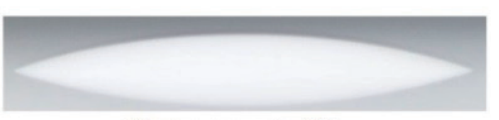

$45 \mathrm{~s}$ treatment: $18^{\circ}$

Fig. 4. Contact angles for mixture of argon and oxygen plasma.

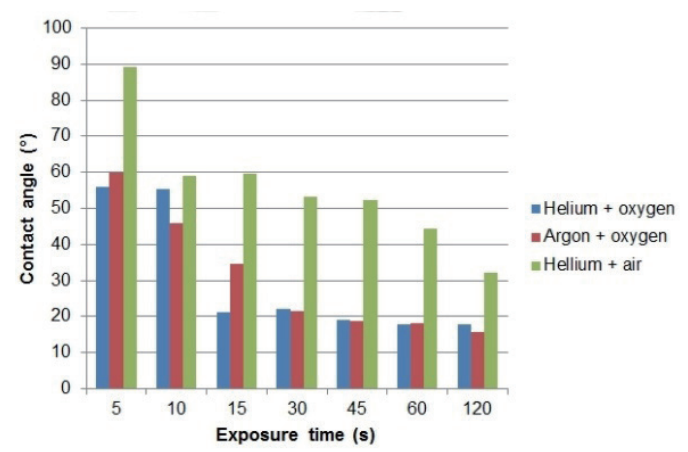

Fig. 5. (Color online) Dependence of contact angle on treatment time for different gas mixtures.

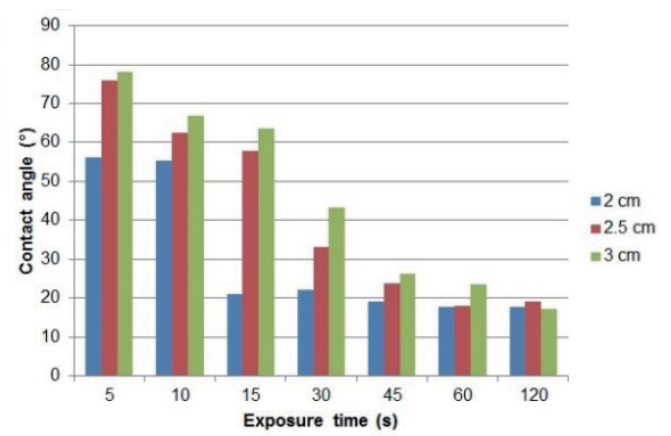

Fig. 7. (Color online) Dependence of contact angle on treatment time for different distances of the surface from the end of reactor.

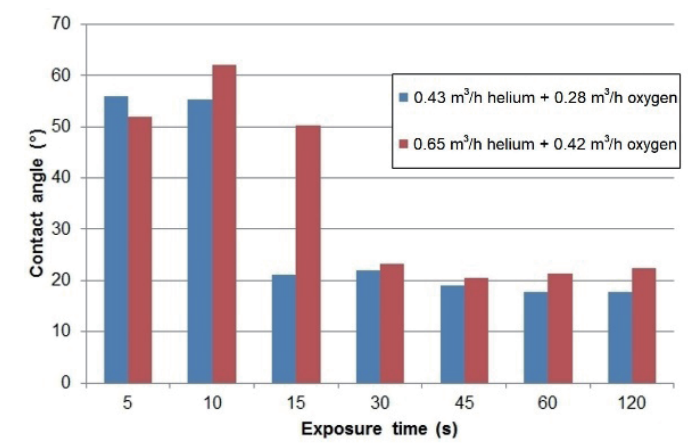

Fig. 6. (Color online) Dependence of contact angle on treatment time for different flow rates.

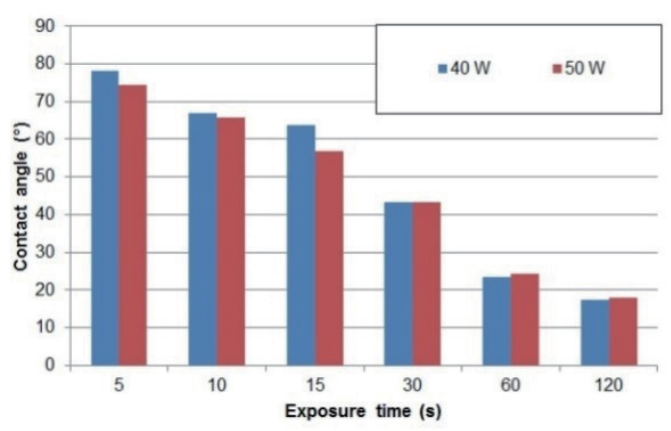

Fig. 8. (Color online) Dependence of contact angle on treatment time for different powers of discharge. 
Figure 9 shows the comparison of the results obtained for a mixture of argon and oxygen immediately after the measurement and after one day from the time of treatment. After one day, the contact angle started to return to its previous value, a behaviour particularly evident at longer exposure times. This may indicate that the effect of plasma treatment on the material does not extend beyond the surface and the process is reversible. Similar results were obtained for a mixture of helium and oxygen (Fig. 10). Results obtained for a mixture of helium and air also showed the return of the contact angle to its previous value, but in this case, the change was smaller due to a smaller effect of the plasma treatment for this mixture (Fig. 11). For this gas mixture, the achieved temperatures were higher and the number of generated active species was lower; thus, the change in surface contact angle just after treatment was smaller than for the mixture of oxygen and helium. However, after $24 \mathrm{~h}$, similar values of surface contact angle for both mixtures were observed. It can be explained by the generation of many short-lived, active species in the case of the oxygen and helium mixture and the consecutive formation of unstable molecular bonds with dynamic character on the surface. However, after one day, comparable amounts of more stable molecular bonds in both mixtures were attained. The change in surface contact angle can be one of the initial steps before the further chemical modification of

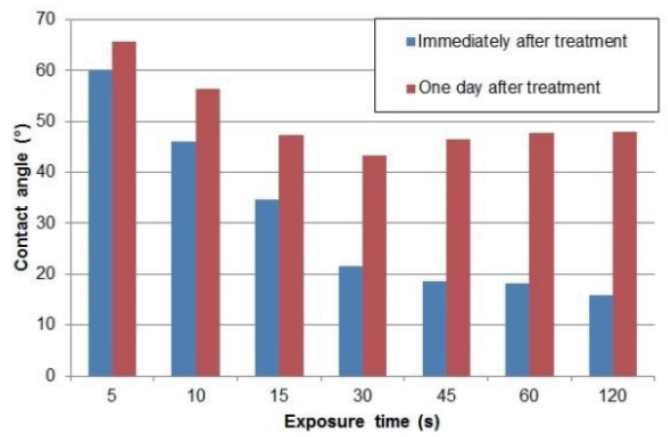

Fig. 9. (Color online) Dependence of contact angle on treatment time immediately after the measurement and after one day $\left(0.43 \mathrm{~m}^{3} / \mathrm{h}\right.$ argon $+0.28 \mathrm{~m}^{3} / \mathrm{h}$ oxygen).

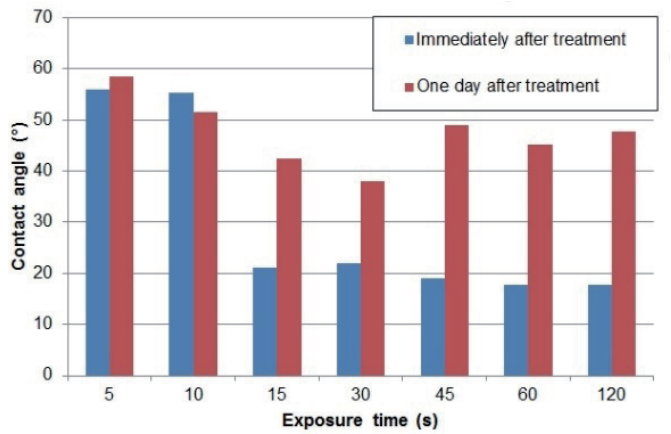

Fig. 10. (Color online) Dependence of contact angle on treatment time immediately after the measurement and after one day $\left(0.43 \mathrm{~m}^{3} / \mathrm{h}\right.$ helium $+0.28 \mathrm{~m}^{3} / \mathrm{h}$ oxygen).

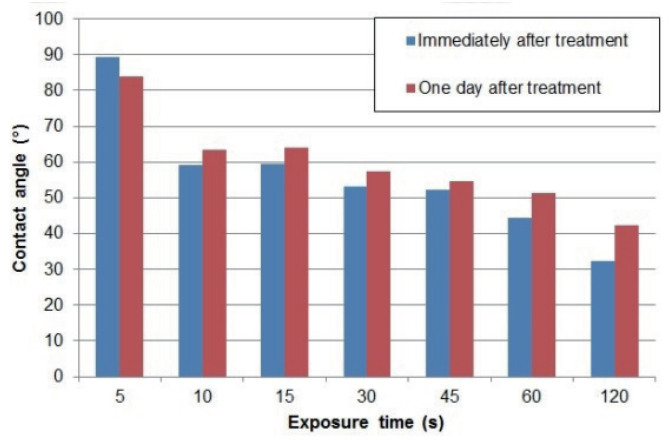

Fig. 11. (Color online) Dependence of contact angle on treatment time immediately after the measurement and after one day $\left(0.43 \mathrm{~m}^{3} / \mathrm{h}\right.$ helium $+0.28 \mathrm{~m}^{3} / \mathrm{h}$ air $)$. 
material properties. Usage of the oxygen and helium mixture immediately before the chemical procedure can greatly enhance the modification opportunities in comparison with the air and helium mixture.

\section{Conclusions}

The results allow us to conclude that an effective change in contact angle is possible through the use of a radio-frequency APPJ source. Significant changes in the angle could be seen for a treatment time of $15 \mathrm{~s}$, which may be important in reducing the cost of modifying lowcost materials such as HIPS. In this study, the most important role in surface modification is played by the composition of the working gas, which determines the number of reactive species involved in changing the hydrophobicity of the material.

\section{Acknowledgments}

This study has been supported by Inkubator Innowacyjności+, KONNECT, M.Era-Net and CEEPUS CIII-AT-0063.

\section{References}

1 N. T. Kakhramanov, R. V. Alieva, and Sh. R. Bagirova: Int. Polym. Sci. Tech. 38 (2011) 20.

2 J. Pawłat: Przegląd Elektrotechniczny 10b (2012) 139.

3 H. Stryczewska: Technologie plazmowe w energetyce i inżynierii środowiska (Wydawnictwo Politechniki Lubelskiej, Lublin, 2009).

4 J. Pawłat: Eur Phys J. Appl. Phys. 61 (2013) 11.

5 J. Pawłat, R. Samoń, H. Stryczewska, J. Diatczyk, and T. Giżewski: Eur. Phys. J. Appl. Phys. 61 (2013) 6.

6 Z. Kolacinski, L. Szymanski, and G. Raniszewski: Eur. Phys. J. Appl. Phys. 61 (2013) 7.

7 K. Gotoh, A. Yasukawa, and K. Taniguchi: J. Adhes. Sci. Technol. 25 (2011) 307.

8 T. Jacobs, R. Morent, N. De Geyter, T. Desmet, S. Vlierberghe, P. Dubruel, and C. Leys: J. Adhes. Sci. Technol. 26 (2012) 2239.

9 N. L. Singh, S. M. Pelagade, R. S. Rane, S. Mukherjee, U. P. Deshpande, V. Ganeshan, and T. Shripathi: Pramana-J. Phys. 80 (2013) 133.

10 E. Anzawa, M. Kral, A. Ogino, and M. Nagatsu: Electr. Eng. Jpn. 176 (2011) 1.

11 C. Cheng, Z. Liye, and R.-J. Zhan: Surf. Coat. Technol. 200 (2006) 6659.

12 J. Abenojar, R. Torregrosa-Coque, M. A. Martínez, and J. M. Martín-Martínez: Surf. Coat. Technol. 203 (2009) 2173.

13 T. Takamatsu, H. Hirai, R. Sasaki, H. Miyahara, and A. Okino: IEEE Trans. Plasma Sci. 41 (2013) 119.

14 Larsson and H. Dérand: J. Colloid Interface Sci. 246 (2002) 214.

15 E. Gonzalez, M. D. Barankin, P. C. Guschl, and R. F. Hicks: Langmuir 24 (2008) 12636.

16 K. D. Weltmann, E. Kindel, T. von Woedtke, M. Hahnel, M. Stieber, and R. Brandenburg: Pure Appl. Chem. 82 (2010) 1223.

17 P. Slepička, N. Kasálková, Slepčková, E. Stránská, L. Bačáková, and V. Švorčík: Express Polym. Lett. 7 (2013) 535.

18 S. K. Øiseth, A. Krozer, B. Kasemo, and J. Lausmaa: Appl. Surf. Sci. 202 (2002) 92.

19 A. S. Lozhkomoev, E. A. Glazkova, E. G. Khorobraya, M. I. Lerner, A. N. Maltsev, and V. G. Podkovyrov: Russ. Phys. J. 56 (2013) 384.

20 J. Kong, K. L. Yung, Y. Xu, and W. Tian: Express Polym. Lett. 4 (2010) 753.

21 O. Kylián, O. Polonskyi, J. Kratochvíl, A. Artemenko, A. Choukourov, M. Drábik, P. Solař, D. Slavínská, and H. Biederman: Plasma Processes Polym. 9 (2012) 180.

22 D. L. Williams, A. T. Kuhn, M. A. Amann, M. B. Hausinger, M. Konarik, and E. I. Nesselrode: Galvanotechnik 101 (2010) 2502. 
23 Y. Yuan and T. R. Lee: Springer Ser. Surf. Sci. 51 (2013) 3.

24 J. Shang, M. Flury, J. B. Harsh, and R. L. Zollars: J. Colloid Interface Sci. 328 (2008) 299.

25 Plastics Group: http://www.plastics.pl/content/zdjecia/file/katalog_tworzywa_techniczne_32_34.pdf (accessed December 2017). 